\title{
Gene expression analysis in NSAID-induced rat small intestinal disease model with the intervention of berberine by the liquid chip technology
}

\author{
Guanqun Chao', Qianqian Wang ${ }^{2}$, Fangxu Ye ${ }^{2}$ and Shuo Zhang ${ }^{2^{*}}$
}

\begin{abstract}
Objective: Investigate the effect and mechanism of berberine on the small intestinal mucosa of non-steroidal antiinflammatory drugs (NSAIDs) related small intestinal injury.

Materials and methods: Twenty-four SD rats were randomly divided into control group, model group and intervention group. The model group and intervention group were treated with diclofenac $(7.5 \mathrm{mg} / \mathrm{kg} \cdot \mathrm{d}, 2 / \mathrm{d})$, a total of 4 days tube feeding, and the intervention group was treated with $50 \mathrm{mg} / \mathrm{kg} \cdot \mathrm{d}$ intragastric administration of berberine after 2 days. The control group was treated with $7.5 \mathrm{mg} / \mathrm{kg} \cdot \mathrm{d}, 2 / \mathrm{d} 0.9 \%$ saline tube feeding. Then we screened differential expression of colonic mucosal gene by the liquid chip technology.

Results: Compared with the control group, macroscopic and histology score of the model group increased significantly $(P<0.05)$, HTR4, HTR1a, F2RL3, CALCA, NPY, CRHR2, IL1b, P2RX3, TPH1, HMOX1, TRPV1, VIP, F2RL1, SLC6A4, TFF2, AQP8 content were significantly increased $(P<0.05)$, NOS1 content decreased significantly $(P<0.05)$; Compared with the model group, macroscopic and histology score of the intervention group improved significantly $(P<0.05)$, and HTR4, F2RL3, NPY, CRHR2, IL1 b, VIP, AQP8 content were significantly lower $(P<0.05)$, NOS1 content increased significantly $(P<0.05)$.

Conclusion: Berberine has a protective effect on NSAID-associated small intestinal injury, the mechanism may be that berberine decreases the expression of intestinal mucosa HTR4, F2RL3, NPY, CRHR2, IL1b, VIP, AQP8, and increases the expression of NOS1, that to reduce intestinal permeability and protect intestinal mucosal barrier.
\end{abstract}

Keywords: NSAID-induced small intestinal disease, Berberine, Gene, The liquid chip technology

\section{Introduction}

Non-steroidal anti-inflammatory drugs (NSAIDs) is a kind of anti-inflammatory drug that does not contain steroid structure, which is widely known that have effect on anti-inflammatory, anti-rheumatism, alleviating pain, pyretolysis and anticoagulated blood and so on. With

\footnotetext{
* Correspondence: zhangshuotcm@163.com

${ }^{2}$ Department of Gastroenterology, The First Affiliated Hospital, Zhejiang Chinese Medical University, Youdian Road No. 54, Hangzhou 310006, China Full list of author information is available at the end of the article
}

the wild application of NSAIDs in rheumatoid arthritis, cardiovascular and cerebrovascular diseases, its adverse reactions are also exposed. These side effects involve the digestive system, blood system, skin connective tissue and respiratory system, among which the most common is the adverse reactions of the gastrointestinal tract [1]. In current, NSAIDs is believed to help many patients, but only estimated $25 \%$ of them receive adequate pain relief [2] in fact. NSAID-induced enteropathy is common. It is reported that the incidence of intestinal

C C The Author(s). 2021 Open Access This article is licensed under a Creative Commons Attribution 4.0 International License, which permits use, sharing, adaptation, distribution and reproduction in any medium or format, as long as you give appropriate credit to the original author(s) and the source, provide a link to the Creative Commons licence, and indicate if changes were made. The images or other third party material in this article are included in the article's Creative Commons licence, unless indicated otherwise in a credit line to the material. If material is not included in the article's Creative Commons licence and your intended use is not permitted by statutory regulation or exceeds the permitted use, you will need to obtain permission directly from the copyright holder. To view a copy of this licence, visit http://creativecommons.org/licenses/by/4.0/ The Creative Commons Public Domain Dedication waiver (http://creativecommons.org/publicdomain/zero/1.0/) applies to the data made available in this article, unless otherwise stated in a credit line to the data. 
damage is up to two-thirds [3]. NSAID-induced small intestinal disease can be manifested as mucosal congestion, edema, erosion and a superficial ulcer formation, severe cases can cause a large area of ulcers, and the clinical manifestations show as abdominal pain, abdominal discomfort, indigestion, diarrhea, gastrointestinal bleeding, perforation and even life-threatening [4].

It is reported that various damage features of the small intestine are common among long-term NSAIDs users: inflammation accounts for $60-70 \%$, ulceration accounts for $30-40 \%$, increased permeability is up to $70 \%$, bleeding/anemia is about $30 \%$, and malabsorption occupies $40-70 \%$ [5] so severe and complex the consequence is, but the mechanism of NSAID-induced small intestinal disease is still unclear. At present, the understanding of the mechanism of NSAID-associated small intestinal injury is mainly focused on the changes of cell membrane permeability, inflammatory reaction, microbial imbalance, and the change of brain gut axi [6].

A lot of research on the mechanism of NSAID-induced small intestinal injury and therapeutic method had been made through experiments and clinical capsule studies. And selective COX-2 inhibitors, prostaglandin derivatives, cytoprotective drugs, PhosphatidylcholineNSAID, and probiotics all shown to have potential protective effects on NSAID-induced small intestinal injury. However, no new promising and standardized drugs had been developed for NSAID-associated small intestinal injury until recently [7]. Berberine, an isoquinoline alkaloid, is a major bioactive component of Coptidis Rhizome which is commonly used as an herbal medicine for treating diarrhea and bacterial and parasitic infections [8]. It has wide biological and pharmacological actions, including preventing 2,4,6-trinitrobenzene sulfonic acid (TNBS)-induced colitis [9], reducing cholesterol levels [10], improving glucose metabolism [11], attenuating autoimmune encephalomyelitis [12]. Clinically, berberine can alleviate the abdominal pain, diarrhea and other symptoms caused by NSAID-induced small intestinal injury, but the specific mechanism is unknown.

Therefore, our present study aims to screen differential expression of small intestinal mucosa gene by the liquid chip technology so as to build a gene regulatory network for NSAID- induced small intestinal disease. Meanwhile, investing the specific mechanism of berberine to prove it has effective therapeutic effects from the gene level.

\section{Methods}

\section{Experimental animal}

Twenty-four female Sprague Dawley (SD) rats (200-220 g,12 weeks old), provided by Animal Experiment Center of Zhejiang Chinese Medicine University, without feeding drugs or used as experimental animals, were kept in room cages at $22-24{ }^{\circ} \mathrm{C}$, humidity $<60 \%$, noise $<$ 50db. Rats were fed with standard diet and distilled water. The rats were acclimatized for a week before the start of the experiment, and were divided randomly into three groups, the control group $(n=8)$, the model group $(n=8)$ and the intervention group $(n=8)$. This study was reviewed and approved by the Medical ethics committee of Zhejiang Chinese Medical University. All sections of this report follow the ARRIVE Guidelines for reporting animal research.

\section{Groups dividing and disposal Control group}

$8 \mathrm{SD}$ normal rats in the control group was tube feeding with $7.5 \mathrm{mg} / \mathrm{kg} \cdot \mathrm{d}, 2 / \mathrm{d} 0.9 \%$ saline for $4 \mathrm{~d}$

\section{Model group}

Dissolving diclofenac sodium (Daifen, Fujisawa German companies, the National Yao Zhtmzi J20050064) into $0.9 \%$ saline. Referring to the long-term of human oral dose $(150 \mathrm{mg} / \mathrm{d})$, and converting into rats oral dose 7.5 $\mathrm{mg} / \mathrm{kg} \cdot \mathrm{d}, 2 / \mathrm{d}$, a total of $4 \mathrm{~d}$ tube feeding preparation model of intestinal injury in $8 \mathrm{SD}$ rats.

\section{Intervention group}

After $2 \mathrm{~d}$ of diclofenac sodium tube feeding, the berberine (Hangzhou Minsheng Pharmaceutical Group Co. Ltd) crushed dissolved in $0.9 \%$ saline, $50 \mathrm{mg} / \mathrm{kg} \cdot \mathrm{d}$ tube feeding to $8 \mathrm{SD}$ rats for $2 \mathrm{~d}$.

All rats were fasted for $24 \mathrm{~h}$, and put to death by intraperitoneal injection of $1 \%$ pentobarbital sodium on 5 th day. Opening the rats' abdominal cavity cutting $2 \mathrm{~cm}$ bowel from the ileocecal valve $5 \mathrm{~cm}$, taking intestinal mucosa macroscopic and histology evaluation.

\subsection{Macroscopic and histology evaluation}

Anatomical lesion score from Wallace et al. [13] was used to calculate the damage of rats' small intestinal mucosal: ulceration: 0 score (normal appearance); 1 score (focal hyperaemia without ulcers); 2 scores (ulceration without hyperaemia or bowel wall thickening); 3 scores (one site of ulceration with inflammation); 4 scores (at least two sites of ulceration and inflammation); 5 scores (major sites of damage extending $>1 \mathrm{~cm}$ along the length of the intestine). Damage extended to $>2 \mathrm{~cm}$ along the length of the intestine increases the score by one for each additional $\mathrm{cm}$ of damage. Adhesions: 0 score (no adhesions to surrounding tissue); 1 score (minor adhesions (intestine can be separated from other tissueseasily)); 2 scores (major adhesions).

Each intestinal segment was processed into paraffin. Preparing Serial paraffin sections $(4 \mu \mathrm{m})$ and staining with hematoxylin-eosin and PAS for morphological examination. Chiu scale [14] was used to assess histologic damage by two observers. 0 , normal mucosa; 1 , 
development of sub-epithelial (Gruenhagen's) spaces; 2, extension of the sub-epithelial space with moderate epithelial lifting from the lamina propria; 3, extensive epithelial lifting with occasional denuded villi tips; 4, denuded villi with exposed lamina propria and dilated capillaries; and 5, disintegration of the lamina propria, appearance of hemorrhageand ulceration.

\section{Experimental procedure}

The main procedure was as below: High-throughput sequencing was conducted on independent samples. Total ribonucleic acid (RNA) was extracted from duodenal tissues through TRIzol (Invitrogen, Gaithersburg, MD, USA) onestep method. Then we did primer test and sample assay. After purification, RNA concentration was analyzed by Nanodrop (Nanodrop Technologies, Wilmington, DE) and quality testing was conducted by using BioAnalyzer (Agilent Technologies, Palo Alto, CA). SuperScript II reverse transcriptase was used to synthesize complementary DNA(cDNA). Luminex 100TM was used to detect the gene expression of intestinal mucosa.

\section{Statistical analysis}

The data of normal distribution was demonstrated as ${ }^{-} \mathrm{x} \pm \mathrm{SD}$, and was analysed by using one-factor analysis of variance. The data of nonnormal distribution was demonstrated by median and full range with using rank sum test, $P<0.05$ showed that the difference had statistical significance.

\section{Results}

\section{Macroscopically visible lesions}

In model group, diclofenac lead to damage including erosion and ulcer in the small intestinal mucosa. Ulcers were more frequently in ileum and predominantly located along the mesenteric border, and the berberine could improve the injury of small intestine. The model group $(5.86 \pm 0.59)$ had higher scores than the control group $(0.86 \pm 0.24)(P<0.05)$. The lesion scores of small intestinal mucosal of berberine intervention group $(2.57 \pm 0.33)$ was significantly lower $(P<$ 0.05) compared with the model group (Fig. 1A).

\section{Histologic damage}

Microscopic examination confirmed that diclofenac could induce severe damage to the rat intestinal mucosa. Histology revealed the villi deficiency, epithelial stratification, basal lamina degeneration, and infiltration with neutrophils. Figure 2 showed an example of lesion in three groups. The results of assessing structural damage were as follows: control group $(0.24 \pm 0.07)$, model group $(4.41 \pm 0.29)$, berberine group $(1.61 \pm 0.26)$. Damage in model group was significantly higher than control group $(P<0.05)$. Compared with model group,the histological scores of berberine were lower $(P<0.05)$ (Fig. 1B).

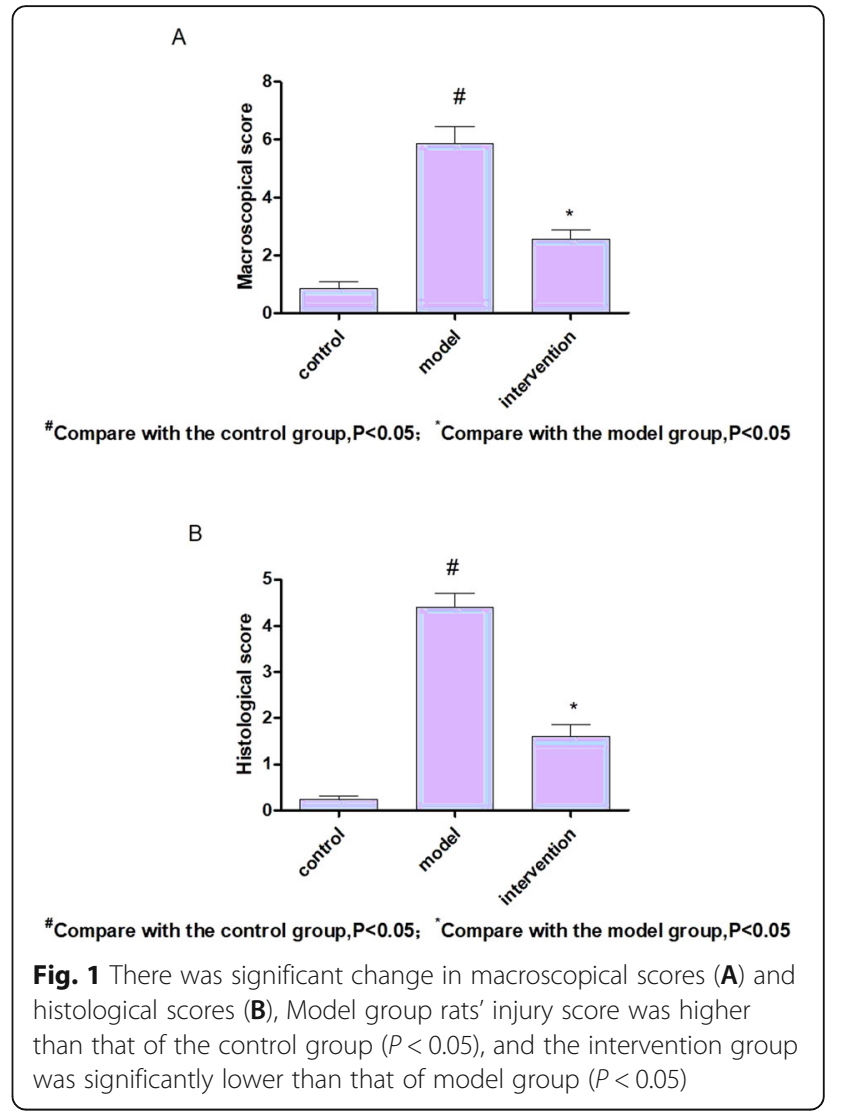

Model rats had obviously shortened and damaged villi in the small intestine.

\section{The screening of genes and statistical analysis}

The results of quantitative gene detection and data analysis was listed in Table 1. We screened HTR4, HTR1A, F2RL3, NOS1, CALCA, NPY, CRHR2, IL1B, P2RX3, NOS2, TPH1, CRHR1, HMOX1, TRPV1, VIP, F2RL1, TGFB1, HTR3A, SLC6A4, TFF2, AQP8 from the small intestine. Rats with NSAID-induced small intestinal disease showed lower levels of $\operatorname{NOS} 1(P<0.05)$, and higher levels of HTR4, HTR1a, F2RL3, CALCA, NPY, CRHR2, IL1b, P2RX3, TPH1, HMOX1, TRPV1, VIP, F2RL1, SLC6A4, TFF2, AQP8 $(P<0.05)$. After berberine intervention, HTR4, F2RL3, NPY, CRHR2, IL1b, VIP, AQP8 were significantly decreased $(P<0.05)$, and NOS1 were significantly increased $(P<0.05)$ (See Table 2$)$.

\section{Discussion}

It is revealed that more than 29 million adults (12.1\%) regular used NSAIDs and around 43 million adults $(19.0 \%)$ took aspirin more than 3 months $>3$ times per week). Widespread use of NSAIDs has increased the damage to the digestive tract such as small intestine which worth our attention [3]. Nevertheless, there is no effective treatment for NSAID-induced small intestinal injury 

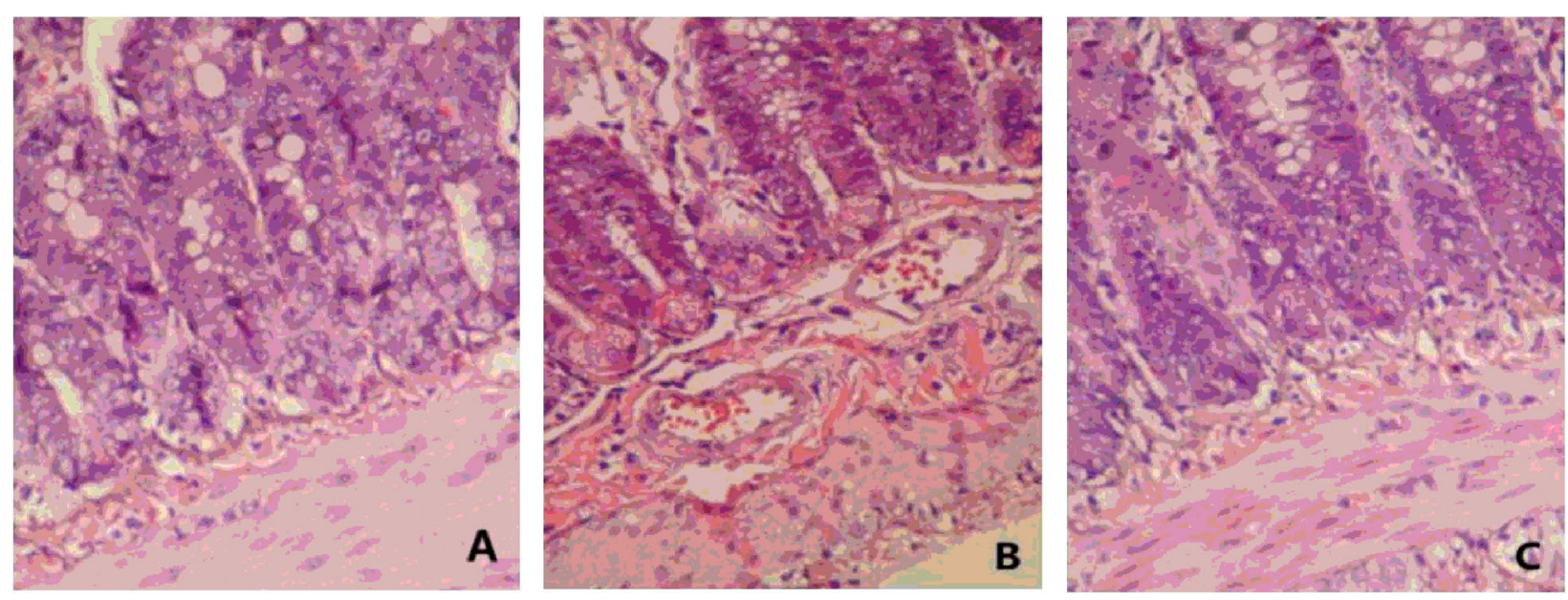

Fig. 2 Light micrographs of rat small intestine demonstrating. A Normal structure; B Enteric tissue after NSAIDs administrating: histology revealed the defect of the villi, epithelial stratification, basal lamina degeneration, and infiltration with neutrophils with diclofenac alone; $\mathbf{C}$ Enteric tissue after berberine intervention: the above pathological changes were improved than those in the model group

because of the complex and indefinite pathogenesis. The aim of this study was to study the specific mechanism of NSAID-induced small intestinal disease and berberine on NSAID-associated small intestinal injury from the gene level. However, previous studies in the literature, including those in our research group, only involved one or two genes. Through literature search, we gathered statistics about differential expression of RNAs in intestinal mucosal tissues and cells in regards to intestinal mucosal barrier injury, intestinal inflammation, gastrointestinal cancer, and inflammatory bowel disease. Therefore, we choose 21 RNAs in rats as study targets [15-26]: HTR4, HTR1a, F2RL3, NOS1, CALCA, NPY, CRHR2, IL1b, P2RX3, NOS2, TPH1, CRHR1, HMOX1, TRPV1, VIP, F2RL1, TGFB1、HTR3a, SLC6A4, TFF2, AQP8. Screening by liquid chip technology, we found that NSAIDs resulted in intestinal damage was associate with HTR4, HTR1a, F2RL3, CALCA, NPY, CRHR2, IL1b, P2RX3, TPH1, HMOX1, TRPV1, VIP, F2RL1, SLC6A4, TFF2, AQP8, NOS1, and berberine treat NSAID- induced small intestinal disease by regulating HTR4, F2RL3, NPY, CRHR2, IL1b, VIP, AQP8, NOS1.

Our experiments have confirmed that the pathogenesis of NSAID-induced small intestinal disease is related to intestinal motility abnormalities, increases permeability of the intestinal mucosa caused by neuroendocrine, inflammatory reactions and disorders of water metabolism. The 5-Hydroxytryptamine Receptor 4(HTR4) and 5Hydroxytryptamine Receptor 1a(HTR1a) produce a sustained excitatory response by activating protein kinase A and binding to 5-Hydroxytryptamine (5-HT). In this experiment, the expression of HTR4 and HTR1a in the ileum mucosa increased, which suggested that NSAIDs mediated the intestinal nervous system to control the movement of intestinal chromaffin cells and increased the excitability of intestinal motility, and then caused intestinal motility dysfunction [27]. As well as Transient Receptor Potential Cation Channel Subfamily V Member 1(TRPV1) has been found to negatively influence the gastrointestinal muscle contractions [28]. Aquaporin 8(AQP8) proteins was found in the apical brush border membrane of intestinal epithelial cells. Increased AQP8 makes liquid water metabolic abnormalities and disturbs the permeability of intestinal mucosa [29]. Other gene F2RL3, CALCA, NPY, CRHR2, IL1b, P2RX3, TPH1, HMOX1, VIP, F2RL1, SLC6A4, TFF2, NOS1 affect the permeability of intestinal mucosa by different ways and accelerate the occurrence of NSAID-induced intestinal injury [30]. For example, Calcitonin gene-related polypeptide-alpha (afa-CGRP) encoded by the Calcitonin Related Polypeptide Alpha (CALCA) gene is shown a potent vasodilator and can mediate neurogenic inflammation [31].

The liquid chip technology is an easier and more costeffective alternative to purchasing and running several real-time instruments in parallel. In conclusion, while testing clinical specimens, the Luminex assay shows clinical sensitivity and specificity comparable to real-time Reverse Transcription-Polymerase Chain Reaction (RT$\mathrm{PCR})$. The assay can process large numbers of specimens at the same time, while significantly reducing the cost. Furthermore, the platform's flexibility allows for the possibility of adding more targets and of easily changing primer sequences in order to detect more genes at the same time [32].

Berberine, which is extracted from traditional Chinese medicine Rhizoma coptidis, is usually used to treat gastrointestinal disorders, due to its antimicrobial 
Table 1 Target genes, amplicon sizes, labels, and sequences of primers and probes used in the Luminex assay

\begin{tabular}{|c|c|c|c|}
\hline Target genes & Amplicon size (bp) & labels & Sequence $\left(5^{\prime}-3^{\prime}\right)$ \\
\hline \multirow[t]{3}{*}{ HTR4 } & 132 & Forward & TCCTCATGGTGCTGGCCTAT \\
\hline & & Reverse & GATGTGTGCTGTGCTGGTCA \\
\hline & & Probe & AACGGGCAGGAGCCACCTCTGAAAGCA \\
\hline \multirow[t]{3}{*}{ HTR1a } & 122 & Forward & CTCCACTTTCGGCGCTTTCT \\
\hline & & Reverse & CCGCTCCCTTCTITTCCACC \\
\hline & & Probe & TCTTCAGAGCCGCGCGCTTCCGAAT \\
\hline \multirow[t]{3}{*}{ F2RL3 } & 145 & Forward & GTACTGTTCTCGGCAGTGGC \\
\hline & & Reverse & CTACGCAGCTGTTGAGGGTG \\
\hline & & Probe & TATGGAGCCTATGTGCCCAGCCTGGCA \\
\hline \multirow[t]{3}{*}{ NOS1 } & 111 & Forward & ATCAGCCAGCAAAGACCAGC \\
\hline & & Reverse & TTAGCCTGGGAGACTGAGCC \\
\hline & & Probe & TCCCAGTAACGGACCTCAGCATGCCCA \\
\hline \multirow[t]{3}{*}{ CALCA } & 103 & Forward & AACACTGCCACCTGTGTGAC \\
\hline & & Reverse & AGGCTTCAGAGCCCACATTG \\
\hline & & Probe & ATCGGCTGGCAGGTCTGCTGAGCAGAT \\
\hline \multirow[t]{3}{*}{ NPY } & 132 & Forward & CTGGAGGAGAGCTTGTGGGA \\
\hline & & Reverse & CGCCTACTCCACACTCCTCA \\
\hline & & Probe & ATCGGGCAGGAGCCACCGCTGAAATCA \\
\hline \multirow[t]{3}{*}{ CRHR2 } & 94 & Forward & TTGGATGGTGCATTCCCTGC \\
\hline & & Reverse & CCAGCTTCCTTGCCAAACCA \\
\hline & & Probe & TCATCGCCTGGGCAGTTGGCAAACTCT \\
\hline \multirow[t]{3}{*}{ IL $1 \mathrm{~b}$} & 94 & Forward & TCGCAGCAGCACATCAACAA \\
\hline & & Reverse & TCCACGGGAAAGACACAGGT \\
\hline & & Probe & TGGCTGTGGAGAAGCTGTGGCAGCT \\
\hline \multirow[t]{3}{*}{$\mathrm{P} 2 \mathrm{R} \times 3$} & 93 & Forward & GCTGGTATACGGGAACGCTG \\
\hline & & Reverse & AGAACAGTCCCCACTCCCAC \\
\hline & & Probe & ACCATCATCAGCTCGGTGGCTGCCTT \\
\hline \multirow[t]{3}{*}{ NOS2 } & 80 & Forward & ATCACTTCCCCGCCTAGTCC \\
\hline & & Reverse & TCTAGCTCCTGCTGTTCGCT \\
\hline & & Probe & TCGACTGCTCAGCACCCTGGCAGAAGA \\
\hline \multirow[t]{3}{*}{ TPH1 } & 145 & Forward & TGACATCTTCCCCCTGCTGA \\
\hline & & Reverse & CACTCTGTTGGCGCAGAAGT \\
\hline & & Probe & ACTCGCCCGATCAGCTCACTGCGAA \\
\hline \multirow[t]{3}{*}{ CRHR1 } & 140 & Forward & CCTGGCCAGCAATGTCTCTG \\
\hline & & Reverse & TGACGGCAATGTGGTAGTGC \\
\hline & & Probe & ATGGCTACCGGGAATGCCTGGCCAA \\
\hline \multirow[t]{3}{*}{ HMOX1 } & 137 & Forward & TCTGGTATGGGCCTCACTGG \\
\hline & & Reverse & GTCACCCAGGTAGCGGGTAT \\
\hline & & Probe & TCATCCCTTGCACGCCAGCCACACA \\
\hline \multirow[t]{3}{*}{ TRPV1 } & 137 & Forward & TCTGGTATGGGCCTCACTGG \\
\hline & & Reverse & GTCACCCAGGTAGCGGGTAT \\
\hline & & Probe & TCATCCCTTGCACGCCAGCCACACA \\
\hline \multirow[t]{2}{*}{ VIP } & 94 & Forward & TGGAAGCCAGAAGCAAGCCT \\
\hline & & Reverse & GGTGGTCCAAAGAGAGGCCA \\
\hline
\end{tabular}


Table 1 Target genes, amplicon sizes, labels, and sequences of primers and probes used in the Luminex assay (Continued)

\begin{tabular}{|c|c|c|c|}
\hline Target genes & Amplicon size (bp) & labels & Sequence $\left(5^{\prime}-3^{\prime}\right)$ \\
\hline & & Probe & AGTGTGCTGTTCTCTCAGTCGCTGGCC \\
\hline \multirow[t]{3}{*}{ F2RL1 } & 102 & Forward & TAATGGCATGGCCCTCTGGA \\
\hline & & Reverse & ATGACAGAGAGGAGGTCGGC \\
\hline & & Probe & ACACCCCGCCGTGATTTACATGGCCA \\
\hline \multirow[t]{3}{*}{ TGFB1 } & 90 & Forward & ATACGCCTGAGTGGCTGTCT \\
\hline & & Reverse & CGCTGAATCGAAAGCCCTGT \\
\hline & & Probe & ACGTCACTGGAGTTGTACGGCAGTGGC \\
\hline \multirow[t]{3}{*}{ HTR3a } & 141 & Forward & ATAGACCCCCAGCCACCTTC \\
\hline & & Reverse & CCTCCCTTGGTGGTGGAAGA \\
\hline & & Probe & TCAGCCATGGGAAACCACTGCAGCCA \\
\hline \multirow[t]{3}{*}{ SLC6A4 } & 91 & Forward & CATCTTCACGGTGCTTGGCT \\
\hline & & Reverse & GATGAAAAGGAGGCTGGGGC \\
\hline & & Probe & ACGAAGACGTGTCCGAGGTGGCCAAA \\
\hline \multirow[t]{3}{*}{ TFF2 } & 133 & Forward & TCGGAGCAGTGTGTCATGGA \\
\hline & & Reverse & GTGGGAAGAAACACCAGGGC \\
\hline & & Probe & TCGCAAGAATTGTGGGTACCCGGGCA \\
\hline \multirow[t]{3}{*}{ AQP8 } & 96 & Forward & GGCCTTGGGGCTCATCATTG \\
\hline & & Reverse & TTGAGGCCTCCGATCACTGT \\
\hline & & Probe & TCAACCCTGCTGTGTCGCTGGCAGT \\
\hline
\end{tabular}

Table 2 Colonic mucosal gene expression among different groups

\begin{tabular}{llll}
\hline & Control group & Model group & Intervention group \\
\hline HTR4 & $0.073 \pm 0.030$ & $0.383 \pm 0.212^{\mathrm{a}}$ & $0.228 \pm 0.074^{\mathrm{b}}$ \\
HTR1a & $0.137 \pm 0.055$ & $0.608 \pm 0.252^{\mathrm{a}}$ & $0.534 \pm 0.353$ \\
F2RL3 & $0.294 \pm 0.091$ & $1.523 \pm 0.502^{\mathrm{a}}$ & $0.990 \pm 0.295^{\mathrm{b}}$ \\
NOS1 & $1.254 \pm 0.340$ & $0.649 \pm 0.289^{\mathrm{a}}$ & $1.127 \pm 0.315^{\mathrm{b}}$ \\
CALCA & $0.271 \pm 0.123$ & $0.586 \pm 0.314^{\mathrm{a}}$ & $0.578 \pm 0.319$ \\
NPY & $0.243 \pm 0.083$ & $1.126 \pm 0.354^{\mathrm{a}}$ & $0.634 \pm 0.262^{\mathrm{b}}$ \\
CRHR2 & $0.201 \pm 0.078$ & $0.836 \pm 0.333^{\mathrm{a}}$ & $0.538 \pm 0.334^{\mathrm{b}}$ \\
IL1b & $0.006 \pm 0.001$ & $0.082 \pm 0.060^{\mathrm{a}}$ & $0.044 \pm 0.010^{\mathrm{b}}$ \\
P2RX3 & $0.147 \pm 0.059$ & $0.415 \pm 0.272^{\mathrm{a}}$ & $0.366 \pm 0.179$ \\
NOS2 & $0.224 \pm 0.072$ & $0.517 \pm 0.365$ & $0.778 \pm 0.443$ \\
TPH1 & $0.033 \pm 0.012$ & $0.275 \pm 0.231^{\mathrm{a}}$ & $0.299 \pm 0.010$ \\
CRHR1 & $0.005 \pm 0.002$ & $0.028 \pm 0.033$ & $0.006 \pm 0.002$ \\
HMOX1 & $0.495 \pm 0.127$ & $1.616 \pm 0.624^{\mathrm{a}}$ & $1.727 \pm 0.449$ \\
TRPV1 & $0.053 \pm 0.017$ & $0.156 \pm 0.087^{\mathrm{a}}$ & $0.179 \pm 0.109$ \\
VIP & $0.594 \pm 0.185$ & $1.110 \pm 0.406^{\mathrm{a}}$ & $0.438 \pm 0.167^{\mathrm{b}}$ \\
F2RL1 & $0.312 \pm 0.047$ & $1.451 \pm 0.372^{\mathrm{a}}$ & $1.483 \pm 0.460$ \\
TGFB1 & $0.210 \pm 0.050$ & $0.205 \pm 0.099$ & $0.188 \pm 0.050$ \\
HTR3a & $0.204 \pm 0.059$ & $0.162 \pm 0.081$ & $0.136 \pm 0.062$ \\
SLC6a4 & $0.249 \pm 0.086$ & $1.565 \pm 0.553^{\mathrm{a}}$ & $1.416 \pm 0.540$ \\
TFF2 & $0.031 \pm 0.011$ & $0.114 \pm 0.067^{\mathrm{a}}$ & $0.140 \pm 0.088$ \\
AQP8 & $0.227 \pm 0.109$ & $0.856 \pm 0.253^{\mathrm{a}}$ & $0.414 \pm 0.201^{\mathrm{b}}$ \\
\hline P $<0.05$ & 0.09 &
\end{tabular}

${ }^{\mathrm{a}} P<0.05$ compared with control group; ${ }^{\mathrm{b}} P<0.05$ compared with model group propertie [33]. Recently, berberine is demonstrated to have multiple pharmacological activities, including anticancer effect, regulate metabolism of glucose and lipid. Some study hypothesized that berberine makes its various effects in the intestinal tract before being absorbed [34]. Some studies even found that the structural modified berberine can improve its activity. It is believed that novel anticancer drugs based on the natural product berberine with both anti-inflammation and anti-tumor activities can be developed in the near future [35]. In our experiment, NSAID-induced small intestinal disease model rats intervened by berberine showed significantly change in HTR4, F2RL3, NPY, CRHR2, IL1b, VIP, AQP8, NOS1. Furthermore, in our published studies, we found that berberine could protect the intestinal mucosa of NSAIDs users by up-regulating the expressions of PGP9.5, GFAP and GDNF to repair the enteric nervous system [36]. It is known that HTR4 stimulates cyclic Adenosine monophosphate (cAMP) production in response to serotonin 5-HT. 5-HT plays a role in both the central and peripheral nervous systems, and mediates motility, secretion, vasodilation, as well as sensation in the gastrointestinal tract,and it also protects neuro and promote inflammatory in the gut [37]. Currently, drugs target to 5 -HT receptors have been developed to treat the functional gastrointestinal (GI) disorders and pain [38]. 5HT3 and 5-HT4 receptor subtypes are located in the 
wall of the gut and have been most extensively studied [37]. The 5-HT4 receptor, is located on enteric nerve terminals to release neurotransmitter when activated, and mediate chloride secretion and goblet cell degranulation, as well as accelerates the peristaltic reflex [39].

Coagulation factor II receptor-like 3 (F2RL3) encodes a member of the protease-activated receptor subfamily, also known as protease-activated receptor 4(PAR4), which takes partin platelet activation, intimal hyperplasia and inflammation [40]. Some study confirmed that PAR4 present in human's small and large intestine [41]. Recently, it has been found that the neutrophil granule protease cathepsin G3 can stimulate PAR4 [42]. At same time, it links PAR4 activation to the presence of granulocytes [42], which suggests that inflammatory pathophysiological circumstancesmay is associated with PAR4. Previous study showed that IL-1, IL-4, and LPS could increase the expression of Corticotropin Releasing Hormone Receptor 2(CRHR-2) [43]. And CRH secreted after activating CRHR-2 outside the brain had pro-inflammatory actions [44], which could mediate the action of lipopolysaccharide [45], so in intestine CRH-CRHR2 signaling likely played an important role in the progression of inflammation and gastric transit [46]. In human intestine,Interleukin 1 Beta (IL-1b) secretion causes exaggerated inflammatory responses by decreased expression of inhibitors of Nuclear factor kB (NF-kB) [47]. As a known pro-inflammatory cytokines, IL-1B via NF- $\mathrm{KB}$ pathway and cytoskeletal contraction and $\mathrm{TJ}$ opening to increase intestinal permeability [48].

On the contrary, vasoactive intestinal peptide (VIP) has potent anti-inflammatory effects via downregulates TNF- $\alpha$ expression [49] and NF-KB-dependent gene activation [50]. VIP increases expression of the tight junction protein zona and reduces paracellular epithelial permeability in $\mathrm{Caco} 2$ and $\mathrm{HT} 29-\mathrm{Cl}$ to indirectly regulate epithelial permeability [50]. Generally speaking, Neuropeptide Y (NPY) and VIP, including their receptors, play a role in inflammatory signaling and epithelial barrier functions.

In humans, AQP8 protein is found as a water selective channel [51] and is located in the absorptive columnar epithelia in duodenum, jejunum, and colon. Many functions of AQPs in the stomach and intestine physiology is confirmed, including water transfer, gastric juice secretion, barrier function [52]. It has been confirmed that AQP8 might be involved in transepithelial water absorption taking place in the small intestine, and the increased expression of AQP8 show to induce small intestine epithelial barrier [53]. Moreover, the anti-diarrhea effects of emodin [54] and berberine [55], may depend on AQPs to regulate water transport and absorption possibly, via PKA/p-CREB signal pathway [54].

\section{Conclusion}

In summary, multiple genes involved in the pathogenesis of NSAID-induced small intestinal disease, associated with intestinal motility disorder, intestinal barrier damage. Chinese medicine berberine has a protective effect on NSAID-associated intestinal injury, the mechanism may be that berberine decreases the expression of intestinal mucosa HTR4, F2RL3, NPY, CRHR2, IL1b, VIP, $\mathrm{AQP} 8$, and increases the expression of NOS1 through alleviating inflammation, nerve endocrine regulation to reduce intestinal permeability and protect intestinal mucosal barrier.

\section{Abbreviations \\ NSAIDs: Non-steroidal anti-inflammatory drugs; TNBS: 2,4,6-trinitrobenzene sulfonic acid; SD: Sprague Dawley; RNA: Total ribonucleic acid; \\ CDNA: Complementary DNA; HTR4: 5-Hydroxytryptamine Receptor 4; HTR1a: 5-Hydroxytryptamine Receptor 1a; 5-HT: 5-Hydroxytryptamine; TRPV1: Transient receptor potential cation channel subfamily $\vee$ member 1 ; AQP8: Aquaporin 8; afa-CGRP: Calcitonin gene-related polypeptide-alpha; CALCA: Calcitonin Related Polypeptide Alpha; RT-PCR: Reverse Transcription- Polymerase Chain Reaction; CAMP: Cyclic Adenosine monophosphate; Gl: Gastrointestinal; F2RL3: Coagulation factor II receptor-like 3; \\ PAR4: Protease-activated receptor 4; CRHR-2: Corticotropin Releasing Hormone Receptor 2; IL-1b: Interleukin 1 Beta; NF-KB: Nuclear factor kB; VIP: Vasoactive intestinal peptide; NPY: Neuropeptide $Y$}

\section{Acknowledgements}

Not applicable.

\section{Authors' contributions}

Guanqun Chao wrote the article. Qianqian Wang and Fangxu Ye did the experiment. Shuo Zhang guided. The author(s) read and approved the final manuscript.

\section{Funding}

This research was supported by National Natural Science Foundation of China (82074214, 81973598, 81573760); funding from Zhejiang Provincial Natural Science Foundation of China under Grant No.LY18H030001; the Medicine and Health Science and Technology Plan Projects in Zhejiang province (2017KY413), Traditional Chinese Medicine Science and Technology Plan of Zhejiang Province (2017ZA089, 2016ZB071, 2015ZZ012,

2014ZA030);Medical Health Platform Plan Projects of Zhejiang Province (2015RCA020); Zhejiang Provincial Natural Science Foundation of China (LY16H030010).

\section{Availability of data and materials}

The datasets used and/or analysed during the current study are available from the corresponding author on reasonable request.

\section{Declarations}

Ethics approval and consent to participate

The study has been approved by the ethics committee of Zhejiang Chinese medical university.

\section{Consent for publication}

Yes.

\section{Competing interests}

There is no Conflict of Interest.

\section{Author details}

'Department of General practice, Sir Run Run Shaw Hospital, Zhejiang University, Hangzhou, China. ²Department of Gastroenterology, The First Affiliated Hospital, Zhejiang Chinese Medical University, Youdian Road No. 54, Hangzhou 310006, China. 
Received: 10 November 2020 Accepted: 30 June 2021 Published online: 20 July 2021

\section{References}

1. Wang YZ, Sun G, Cai FC, Yang YS. Clinical features, diagnosis, and treatment strategies of gastrointestinal diaphragm DiseaseAssociated with nonsteroidal anti-inflammatory drugs. Gastroenterol Res Pract. 2016;2016: 3679741.

2. Scarpelli R, Sasso O, Piomelli D. A double whammy: targeting both fatty acid amide hydrolase (FAAH) and cyclooxygenase (COX) to TreatPain and inflammation. Chemmedchem. 2016;11:1242-51.

3. Fujimori S, Gudis K, Takahashi Y, Seo T, Yamada Y, Ehara A, et al. Distribution of small intestinal mucosal injuries as a result of NSAID administration. Eur J Clin Investig. 2010;40(6):504-10

4. Wu LL, Yang YS, Cai FC, Wang SF. Gastric body diaphragm-like stricture as a rare complication of nonsteroidal anti-inflammatorydrugs. World J Gastroenterol. 2013;19(23):3703-6.

5. Lanas A, Sopena F. Nonsteroidal anti-inflammatory drugs and lower gastrointestinal complications. Gastroenterol Clin North Am. 2009;38:333-52.

6. Yoshikawa K, Kurihara C, Furuhashi H, Takajo T, Maruta K, Yasutake Y, et al. Psychological stress exacerbates NSAID-induced small bowel injury by inducing changes in intestinal microbiota and permeability via glucocorticoid receptor signaling. J Gastroenterol. 2017;52(1):61-71.

7. Lim YJ, Chun HJ. Recent advances in NSAIDs-induced Enteropathy therapeutics: new options, New Challenges. Gastroenterol Res Pract. 2013; 2013:761060.

8. Li YH, Zhang M, Xiao HT, Fu HB, Ho A, Lin CY, et al. Addition of berberine to 5-aminosalicylic acid for treatment of dextran sulfate sodium-induced chronic colitis in C57BL/6 mice. PLoS One. 2015;10(12):e0144101.

9. Lee IA, Hyun YJ, Kim DH. Berberine ameliorates TNBS-induced colitis by inhibiting lipid peroxidation, enterobacterial growth and NF-KB activation. Eur J Pharmacol. 2010;648:162-70.

10. Kong W, Wei J, Abidi P, Lin M, Inaba S, Li C, et al. Berberine is a novel cholesterol-lowering drug working through a unique mechanism distinctfrom statins. Nat Med. 2004;10(12):1344-51.

11. Xia X, Yan J, Shen Y, Tang K, Yin J, Zhang Y, et al. Berberine improves glucose metabolism in diabetic rats by inhibition of hepatic gluconeogenesis. PLoS One. 2011;6:e16556.

12. Ma X, Jiang $Y$, Wu A, Chen X, Pi R, Liu M, et al. Berberine attenuates experimental autoimmune encephalomyelitis in C57 BL/6 mice. PLoS One. 2010;5:e13489.

13. Reuter BK, Asfaha S, Buret A, et al. Exacerbation of inflammation-associated colonic injury in rat through inhibition of cyclooxygenase-2. J Clin Invest. 1996;98(9):2076-85.

14. Chiu CJ, McArdle AH, Brown R, Scott HJ, Gurd FN. Intestinal mucosal lesion in low-flow states. I. A morphological, hemodynamic, and metabolic reappraisal. Arch Surg. 1970;101(4):478-83.

15. Li B, Lee C, Filler T, Hock A, Wu RY, et al. Inhibition of corticotropin-releasing hormone receptor 1 and activation of receptor 2 protect against colonic injury and promote epithelium repair. Sci Rep. 2017;7:46616.

16. Banan A, Fields JZ, Zhang Y, Keshavarzian A. iNOS upregulation mediates oxidant-induced disruption of F-actin and barrier of intestinal monolayers. Am J Physiol Gastrointest Liver Physiol. 2001;280(6):G1234-46.

17. Reigstad CS, Linden DR, Szurszewski JH, et al. Correlated gene expression encoding serotonin $(5-\mathrm{HT})$ receptor 4 and $5-\mathrm{HT}$ transporter in proximal colonic segments of mice across different colonization states and sexes. Neurogastroenterol Motil. 2016;28(9):1443-8.

18. Chandrasekharan B, Nezami BG, Srinivasan S. Emerging neuropeptide targets in inflammation: NPY and VIP. Am J Physiol Gastrointest Liver Physiol. 2013;304(11):G949-57.

19. Kathryn L. Howe, Robert J Lorentz, Amit Assa, et al. transforming growth factor- $\beta 1$ protects against intestinal epithelial barrier dysfunction caused by hypoxia-reoxygenation. Shock. 2015;43(5):483-9.

20. Duan L, Yan Y, Sun YB, Zhao B, Hu WJ, Li GF. Contribution of TRPV1 and multidrug resistance proteins in the permeation of capsaicin across different intestinal regions. Int J Pharm. 2013;445(1-2):134-40.

21. Schulz S, Wong RJ, Jang KY, et al. Heme oxygenase-1 deficiency promotes the development of necrotizing enterocolitis-like intestinal injury in a newborn mouse model. Am J Physiol Gastrointest Liver Physiol. 2013; 304(11):G991-G1001.
22. Buda A, Jepson MA, Pignatelli M. Regulatory function of trefoil peptides (TFF) on intestinal cell junctional complexes. Cell Commun Adhes. 2012; 19(5-6):63-8.

23. Zahn A, Moehle C, Langmann T, et al. Aquaporin-8 expression is reduced in ileum and induced in colon of patients with ulcerative colitis. World $J$ Gastroenterol. 2007;13(11):1687-95.

24. Ammori BJ, Becker $\mathrm{KL}$, Kite $\mathrm{P}$, et al. Calcitonin precursors: early markers of gut barrier dysfunction in patients with acute pancreatitis. Pancreas. 2003; 27(3):239-43.

25. Shinoda M, Bin F, Gebhart GF. Peripheral and central P2X receptor contributions to colon mechanosensitivity and hypersensitivity in the mouse. Gastroenterology. 2009;137(6):2096-104.

26. Carmen Martín M, Oliver J, Mendoza JL, et al. Influence of mutations of proteinase-activated receptors F2R/PAR1 and F2RL1/PAR2 on inflammatory bowel disease. Med Clin (Barc). 2008:131(16):609-11.

27. Zou XP, Chen M, Wei W, Cao J, Chen L, Tian M. Effects of enteral immunonutrition on the maintenance of gut barrier function and immunefunction in pigs with severe acute pancreatitis. JPEN J Parenter Enteral Nutr. 2010;34(5):554-66.

28. Boudaka A, Wörl J, Shiina T, Neuhuber WL, Kobayashi H, Shimizu Y, et al. Involvement of TRPV1-dependent and -independent components in the regulation of vagallyinduced contractions in the mouse esophagus. Eur J Pharmacol. 2007:556(1-3):157-65.

29. Tritto S, Gastaldi G, Zelenin S, Grazioli M, Orsenigo MN, Ventura U, et al. Osmotic water permeability of rat intestinal brush border membrane vesicles: involvement of aquaporin-7 and aquaporin-8 and effect of metal ions. Biochem Cell Biol. 2007:85(6):675-84.

30. Kim JJ, Wang H, Terc JD, Zambrowicz B, Yang QM, Khan WI. Blocking peripheral serotonin synthesis by telotristat etiprate (LX1032/LX1606) reduces severityof both chemical- and infection-induced intestinal inflammation. Am J Physiol Gastrointest Liver Physiol. 2015;309(6):G455-65.

31. Luo XL, Yang TL, Chen XP, Li YJ. Association of CALCA genetic polymorphism with essential hypertension. Chin Med J. 2008;121(15):140710.

32. Munro SB, Kuypers J, Jerome KR. Comparison of a multiplex real-time PCR assay with a multiplex Luminex assay for influenza virus detection. J Clin Microbiol. 2013;51(4):1124-9.

33. Xu JH, Liu XZ, Pan W, Zou DJ. Berberine protects against diet-induced obesity through regulating metabolic endotoxemia and gut hormone levels. Mol Med Rep. 2017;15(5):2765-87.

34. Piao M, Cao H, He N, Yang B, Dong W, Xu M, et al. Berberine inhibits intestinal polyps growth in Apc ( $\mathrm{min} /+)$ mice via regulation of macrophage polarization. Evid Based Complement Alternat Med. 2016;2016:5137505.

35. Zou K, et al. Advances in the study of berberine and its derivatives: a focus on anti-inflammatory and anti-tumor effects in the digestive system. Acta Pharmacol Sin. 2017;38(2):157-67.

36. Chao G, Ye F, Yuan Y, Zhang S. Berberine ameliorates non-steroidal antiinflammatory drugs-induced intestinal injury by the repair of enteric nervous system. Fundam Clin Pharmacol. 2020;34(2):238-48.

37. Mawe GM, Hoffman JM. Serotonin signalling in the gut--functions, dysfunctions and therapeutic targets. Nat Rev Gastroenterol Hepatol. 2013; 10:473-86.

38. Spohn SN, Bianco F, Scott RB, Keenan CM, Linton AA, O'Neill CH, et al. Protective Actions of Epithelial 5-Hydroxytryptamine 4 Receptors in Normal and Inflamed Colon. Gastroenterology. 2016;151(5):933-944.e3.

39. Hoffman JM, Tyler K, MacEachern SJ, Balemba OB, Johnson AC, Brooks EM, et al. Activation of colonic mucosal 5-HT (4) receptors accelerates propulsive motility and inhibitsvisceral hypersensitivity. Gastroenterology. 2012;142(4): 844-854.e4.

40. Leger AJ, Covic L, Kuliopulos A. Protease-activated receptors in cardiovascular diseases. Circulation. 2006;114:1070-7.

41. Xu WF, Andersen $H$, Whitmore TE, Presnell SR, Yee DP, Ching A, et al. Cloning and characterization of human protease-activated receptor 4 . Proc Natl Acad Sci U S A. 1998;95(12):6642-6.

42. Mulè F, Pizzuti R, Capparelli A, Vergnolle N. Evidence for the presence of functional protease activated receptor 4 (PAR4) in the rat colon. Gut. 2004; 53(2):229-34.

43. Papadopoulou NG, Oleson L, Kempuraj D, Donelan J, Cetrulo CL Theoharides TC. Regulation of corticotropin-releasing hormone receptor-2 expression in human cord blood-derived cultured mast cells. J Mol Endocrinol. 2005;35(3):R1-8. 
44. Karalis K, Sano H, Redwine J, Listwak S, Wilder RL, Chrousos GP. Autocrine or paracrine inflammatory actions of corticotropin-releasing hormone in vivo. Science. 1991;254(5030):421-3.

45. Zbytek B, Pfeffer LM, Slominski AT. Corticotropin-releasing hormone stimulates NF-kappaB in human epidermal keratinocytes. J Endocrinol. 2004; 181:1-7.

46. Hussain Z, Kim HW, Huh CW, Lee YJ, Park H. The effect of peripheral CRF peptide and water avoidance stress on colonic and gastric transit in Guinea pigs. Yonsei Med J. 2017;58(4):872-7.

47. Nanthakumar N, Meng D, Goldstein AM, Zhu W, Lu L, Uauy R, et al. The mechanism of excessive intestinal inflammation in necrotizing enterocolitis: an immatureinnate immune response. PLoS One. 2011;6(3):e17776.

48. de Sablet T, Potiron L, Marquis M, Bussière FI, Lacroix-Lamandé S, Laurent F. Cryptosporidium parvum increases intestinal permeability through interaction with epithelialcells and $\mathrm{IL}-1 \beta$ and TNFa released by inflammatory monocytes. Cell Microbiol. 2016;18(12):1871-80.

49. Kim WK, Kan Y, Ganea D, Hart RP, Gozes I, Jonakait GM. Vasoactive intestinal peptide and pituitary adenylyl cyclase-activating polypeptide inhibit tumornecrosis factor-alpha production in injured spinal cord and in activated microglia via a CAMP-dependent pathway. J Neurosci. 2000;20(10): 3622-30.

50. Gonzalez-Rey E, Delgado M. Vasoactive intestinal peptide inhibits cyclooxygenase-2 expression in activated macrophages, microglia, and dendritic cells. Brain Behav Immun. 2008;22:35-41.

51. Elkjaer ML, Nejsum LN, Gresz V, Kwon TH, Jensen UB, Frøkiaer J, et al. Immunolocalization of aquaporin-8 in rat kidney, gastrointestinal tract, testis, and airways. Am J Physiol Renal Physiol. 2001;281(6):F1047-57.

52. Laforenza U. Water channel proteins in the gastrointestinal tract. Mol Asp Med. 2012;33:642-50

53. Wang YH, Liu TT, Kung WM, Chen CC, Wen YT, Lin IC, et al. Expression of aquaporins in intestine after heat stroke. Int J Clin Exp Pathol. 2015;8(8): 8742-53.

54. Zheng YF, Liu CF, Lai WF, Xiang Q, Li ZF, Wang H, et al. The laxative effect of emodin is attributable to increased aquaporin 3 expression in the colon of mice and HT-29 cells. Fitoterapia. 2014;96:25-32.

55. Zhang $Y$, Wang $X$, Sha S, Liang S, Zhao L, Liu L, et al. Berberine increases the expression of NHE3 and AQP4 in sennosideA-induced diarrhoea model. Fitoterapia. 2012;83(6):1014-22.

\section{Publisher's Note}

Springer Nature remains neutral with regard to jurisdictional claims in published maps and institutional affiliations.

Ready to submit your research? Choose BMC and benefit from:

- fast, convenient online submission

- thorough peer review by experienced researchers in your field

- rapid publication on acceptance

- support for research data, including large and complex data types

- gold Open Access which fosters wider collaboration and increased citations

- maximum visibility for your research: over $100 \mathrm{M}$ website views per year

At $\mathrm{BMC}$, research is always in progress.

Learn more biomedcentral.com/submissions 